\title{
Fertilization and normal development in Ascidiella aspersa (Tunicata) studied with Nomarski-optics
}

\author{
Eva Niermann-Kerkenberg* \& Dietrich Kurt Hofmann \\ Lehrstuhl für Spezielle Zoologie \& Parasitologie, Arbeitsgruppe Entwicklungsphysio- \\ logie der Tiere, Ruhr-Universität Bochum; Postfach 1021 48, D-4630 Bochum, \\ Federal Republic of Germany
}

\begin{abstract}
Normal development of Ascidiella aspersa was studied over a period of approx. $24 \mathrm{~h}$ at $20^{\circ} \mathrm{C}$ from egg insemination through metamorphosis of the tadpole larva using Nomarski-optics. Records were made of spermatozoa attaching to and passing through the cellular envelopes and the chorion of the egg. Egg shape alterations upon entry of the fertilizing sperm, which reflect the early phase of ooplasmic segregation, were monitored in intact and dechorionated eggs. The time course of normal development was recorded, and prominent stages were photographed within or deprived of the egg envelopes. The present observations are compared with recent accounts on early development in other solitary ascidian species.
\end{abstract}

\section{INTRODUCTION}

Only a few species of tunicates are endemic to the North Sea coast of Germany, and most of them are restricted to the immediate vicinity of the island of Helgoland. Among these are three species of ascidians which already served for classical investigations in tunicate development at the end of the 19th century. Chabry (1887) performed his epochmaking experiments of developmental potencies of isolated blastomeres at the 2- and 4cell stage on Ascidiella aspersa. Structure and origin of the egg envelopes in Clavelina lepadiformis were studied by Van Beneden \& Julin in 1886, and Castle (1896) detected self-incompatibility in Ciona intestinalis.

Recent descriptions of normal development in the oviparous Ciona intestinalis and the viviparous Clavelina lepadiformis have been published, along with series of colour photomicrographs by Groepler $(1983,1984)$. An excellent SEM-study on early morphogenetic stages of Halocynthia roretzi is available from Satoh (1978). The present paper describes gamete interactions leading to fertilization, formation of polar bodies and the alterations of egg shape related to processes termed ooplasmic segregation in $A$. aspersa. It further provides data on the time course of embryonic, larval and metamorphic development and it includes photomicrographs of prominent developmental stages. Since many of the morphogenetic events described are usually obscured by the two cellular egg envelopes and the chorion, selected stages are shown in dechorionated specimens. This paper finally aims to demonstrate that $A$. aspersa provides a favourable, rapidly developing living material which allows the study of major events of chordate development.

\footnotetext{
* Addressee for reprint orders
} 


\section{MATERIALS AND METHODS}

Adult specimens of Ascidiella aspersa were collected from June to September by divers of the Biologische Anstalt Helgoland (BAH) in the South Harbour area of Helgoland (North Sea). All observations and experiments reported in this paper were carried out at the guest laboratories of the BAH.

To obtain mature gametes, the self-fertile hermaphroditic individuals were sectioned as illustrated in Figure 1: The tunic was opened by a longitudinal cut extending from the atrial siphon to the oral siphon. In contrast to Ciona intestinalis, the tunic is not tightly connected with the rest of the animal and can easily be removed. The body of the ascidian was placed in a plastic Petri dish containing a layer of wax, pinned so that the atrial siphon was lying to the right, and covered with seawater. A sac-like ovary lying in the intestinal loop as in $C$. intestinalis was not found in $A$. aspersa, but the gonoducts could be discovered following the hind gut to the atrial siphon. If the gonads were ripe, the vas deferens was seen as an opaque white line and the overlying oviduct was tightly filled with eggs. First the oviduct was punctured with fine forceps and the eggs were collected with a pipette, then the sperm were recovered from the vas deferens. The eggs were suspended and fertilized in filtered sea water in Petri dishes. The excess sperm were removed thereafter by rinsing the eggs, which were then kept in Petri dishes in millipore-filtered seawater at $20^{\circ} \mathrm{C}$.

Egg envelopes from unfertilized eggs were removed chemically by incubating them in trypsin (Sigma Type V-S, $1 \mathrm{mg} / \mathrm{ml}$ ) for one hour, while developing eggs were mechanically dechorionated using tungsten needles.

Sperm-egg interactions and normal development of $A$. aspersa eggs were observed and photographed live using a Zeiss photomicroscope equipped with Nomarski differential interference contrast optics (DIC).

\section{RESULTS}

\section{Morphology of the gametes}

The oocyte of Ascidiella aspersa is surrounded by the egg envelopes consisting of the outer follicle cells, the inner test cells and the interposed chorion. The unfertilized ovum remains in the metaphase of the first meiotic division.

The test cells lying in the perivitelline space next to the oolemma have a spherical or ovoid shape and their cytoplasm contains granules of various size and numerous vacuoles (Fig. 2F). The envelope, called chorion, is a non-cellular layer of fibrillar material that condenses outwards and forms a basement membrane. The follicle cells are attached to this basement membrane and form an epithelium. Since the attachment is not very firm, follicle cells may partly detach during cultivation of the embryos (Fig. 5G). The cytoplasm is mainly localized at the periphery of these strongly vacuolized cells (Fig. 2C).

The mature spermatozoan of $A$. aspersa is divided into a head and a tail, a middle portion is missing. The head contains the nucleus which is surrounded by one large mitochondrion (Fig. 2B). 


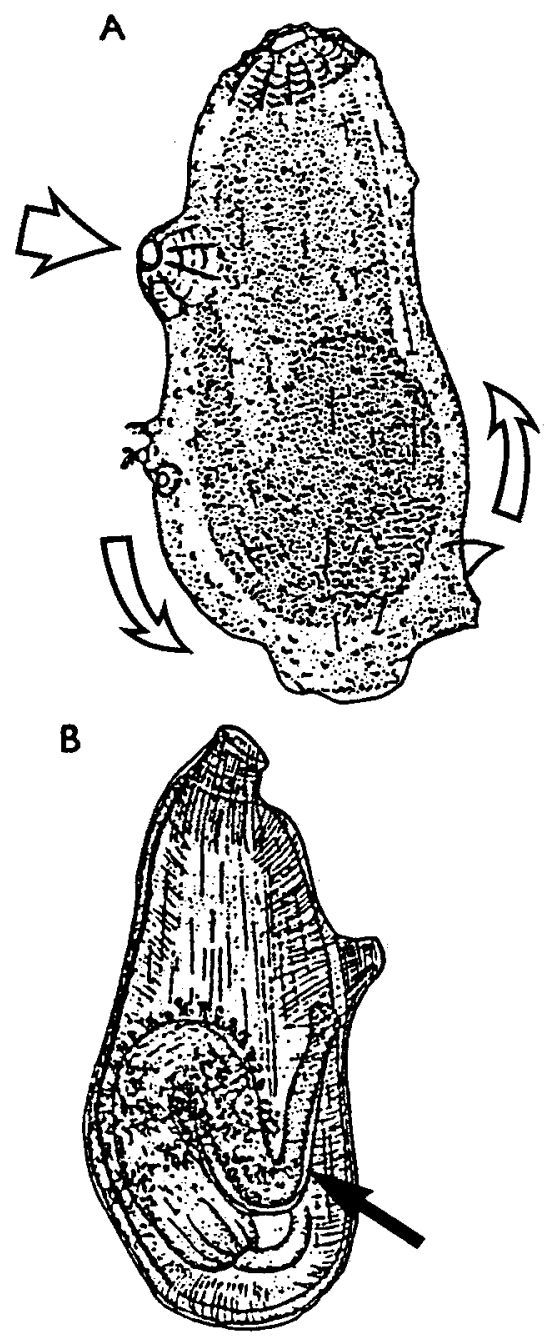

Fig. 1. Preparation of Ascidiella aspersa (after Berrill, 1950). A: Individual within test, about threequarters natural size (arrows indicate the direction of cuts to open the tunic). B: Individual without test, seen from the left side (arrow shows the part of the gonoduct that is punctured)

\section{Fertilization}

Eggs and sperm are released into the ambient water, where fertilization takes place. When reaching the follicle cells, as in the one way traffic system, the spermatozoa move through the intercellular spaces of the follicle cells only in one direction, that is towards the chorion. As soon as they reach the chorion they form a hexagonal pattern corresponding to the boundaries of the follicle cells (Fig. 2A, B). Spermatozoa bind to the chorion with the tips of their heads, but not all of them penetrate the chorion (Fig. 2C). If a spermatozoan passes through, its mitochondrion is shifted to the tail (Fig. 2E). 

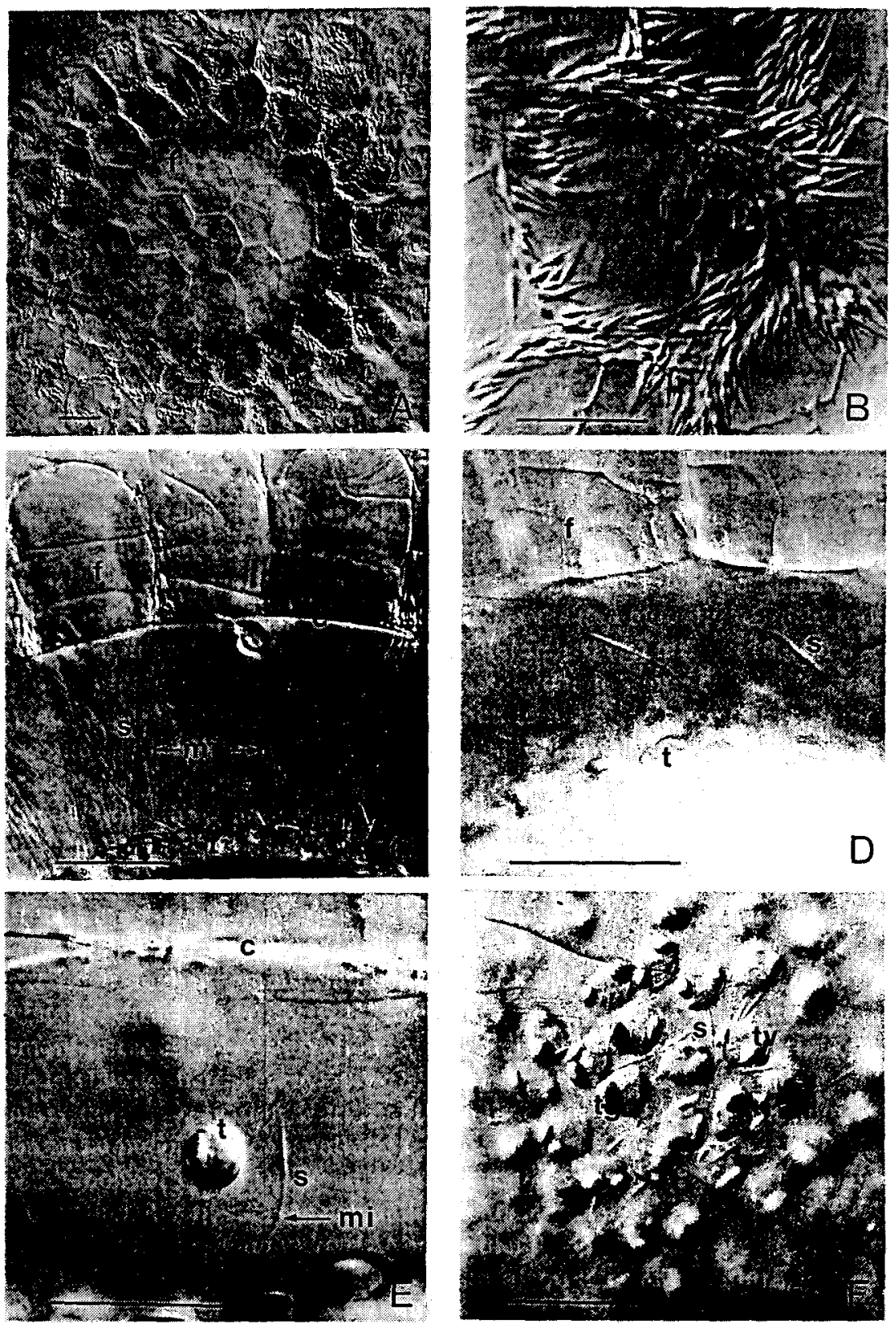

Fig. 2. (A-F). Sperm-egg interactions in Ascidiella aspersa. A: Numerous spermatozoa reaching the follicle cells of an egg. B: Spermatozoa at the boundary of a follicle cell. C: Spermatozoa, passing through the chorion, where the mitochondria are shifted onto the flagella. D: Spermatozoa within the perivitelline space. E: Spermatozoan next to a test cell. F: Spermatozoa, laterally attached to the oolemma between the test cells. c: chorion, f: follicle cell, mi: mitochondrion, s: spermatozoan, $t$ : test cell, tg: test cell granule, tv: test cell vacuole. Scale bars: $10 \mu \mathrm{m}$ 
Within the perivitelline space the spermatozoa are able to move in all directions (Fig. 2D) and to get into contact with the oolemma. Between the test cells they attach to the oolemma laterally by their heads (Fig. 2F).

After the spermatozoan has entered the ovum, one can observe distinct modifications in the shape of the egg (Fig. 3). First it contracts near the animal pole, which can be anticipated by the excentric position of the meiotic aster of the egg nucleus, so that the egg becomes pear-shaped. This constriction spreads over its whole surface along the animal-vegetative axis. Thirty seconds after the first change the animal pole of the egg regains its original form and the equatorial region is now similarly constricted so that the cell looks like a dumb-bell. Another $30 \mathrm{sec}$ later the contraction begins at the vegetative pole. The remaining portion does not undergo any contraction and now the egg is again pear-shaped. After a further $30 \mathrm{sec}$ no constriction can be seen, but a cap of cytoplasm is left behind at the vegetative pole. The cap is seen only for a few minutes and then is withdrawn, so that the egg restores its spherical shape $10 \mathrm{~min}$ after insemination and before the first polar body is extruded.

The cap of cytoplasm is covered by the egg envelopes, especially by the test cells, but can be well seen in dechorionated eggs. The ejection of the polar bodies at the animal pole can only be observed in dechorionated eggs (Fig. 4). Approximately $15 \mathrm{~min}$ after insemination, the egg completes the first meiotic division and ejects the first polar body. Forty-five minutes after insemination, the second polar body is extruded. During this time the egg changes its shape from spherical to ovoid and back again to spherical.

\section{Cleavage}

The first cleavage is preceded by the mitotic division of the zygote nucleus. About $55 \mathrm{~min}$ after insemination the constriction of the first cleavage furrow begins at the animal pole and the furrow deepens until the egg divides into two blastomeres within 5 min. The eggs of Ascidiella aspersa as those of other ascidians cleave bilaterally and symmetrically (Fig. 5). The first two cleavages are meridional but the second cleavage takes place at right angle to the first (Fig. 5A, B). At the third division the egg cleaves equatorially (Fig. 5C), whereas the fourth one is again meridional. The fourth cleavage begins first at the vegetative pole. The 16-cell stage is composed of eight cells of equal size at the animal pole and eight unequal ones at the vegetative pole. The bilateral symmetry of the embryo becomes evident for the first time at this developmental stage (Fig. 5D, E arrows). The 32-cell stage consists of several layers of blastomeres in the direction of the animal-vegetative axis. At the 64-cell stage the spherical embryo is called blastula (Fig. 5F). The blastula possesses a small blastocoel which persists only for a short period of time.

\section{Gastrulation}

After the 64-cell stage the gastrula is formed by invagination and epiboly (Pflugfelder, 1970). First the embryo flattens and then assumes an umbrellar shape (Fig. 5G), because the regularly shaped ectodermal cells of the animal pole move towards the vegetative pole, where the irregularly shaped endodermal cells seem to invaginate. Thus the gastrula with a wide and centrally situated triangular blastopore develops (Fig. $5 \mathrm{H}$ ). During gastrulation the blastopore becomes narrow and is shifted by cellular movements 

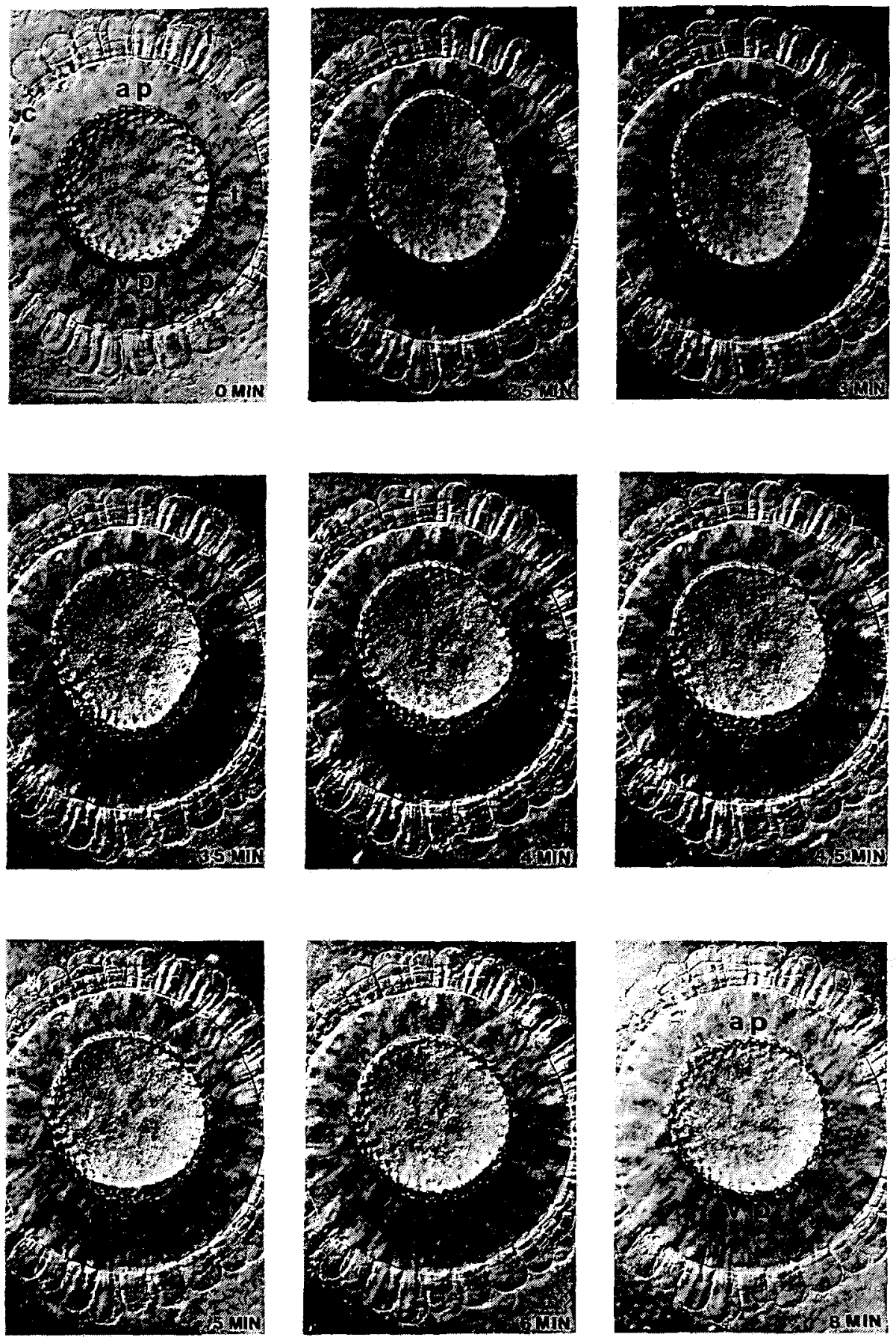

Fig. 3. Modifications of the egg shape following sperm entry in Ascidiella aspersa, The time recorded is in minutes after insemination. For details, see text. Scale bar $20 \mu \mathrm{m}$ for all figures. ap: animal pole, c: chorion, $\mathrm{f}$ : follicle cell, $\mathrm{t}$ : test cell, $\mathrm{vp}$ : vegetative pole, $\mathbf{\Delta}$ : cap of cytoplasm 

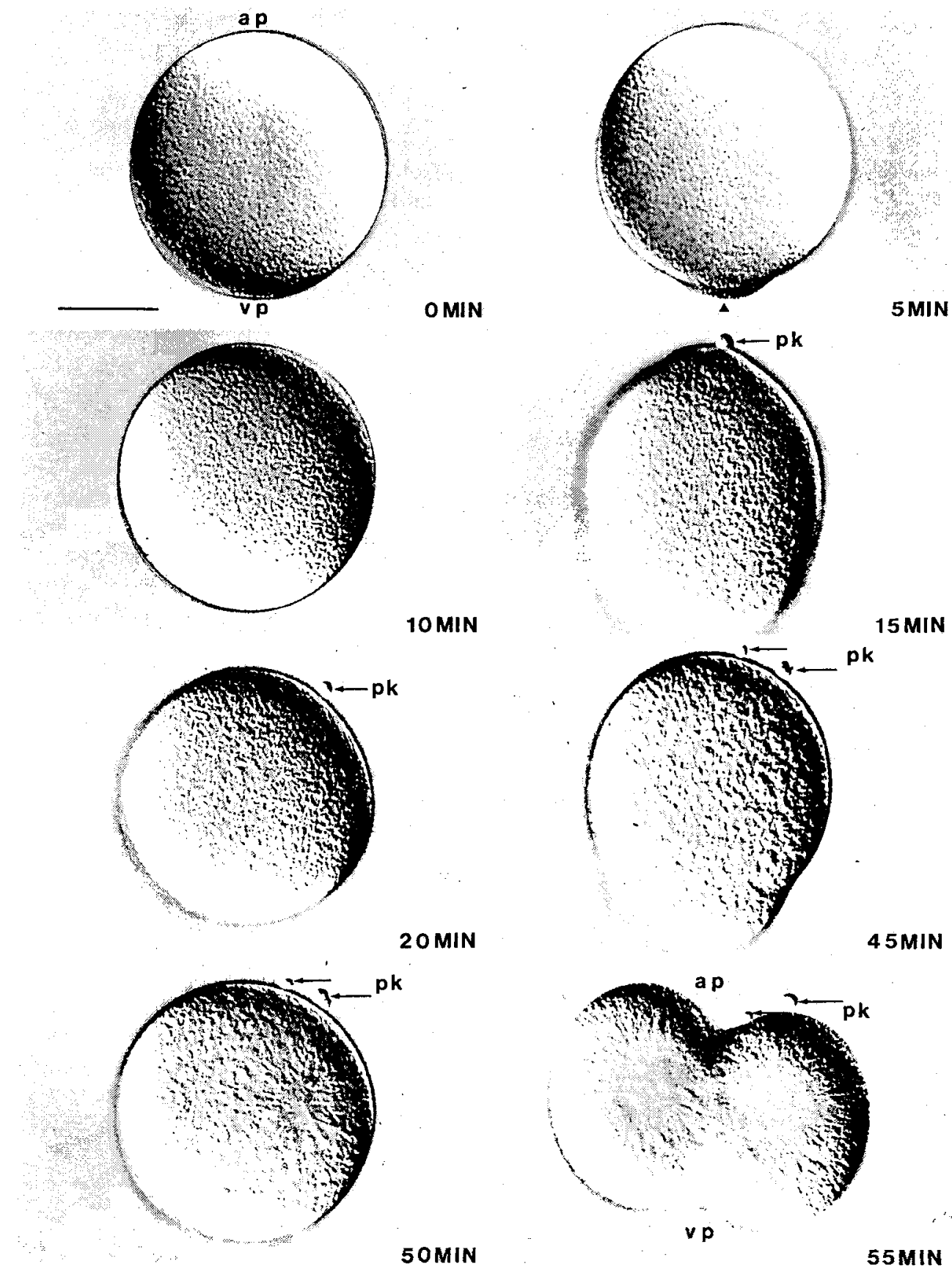

15 MIN

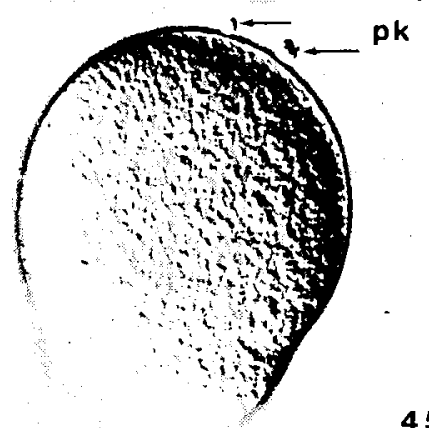

45 MIN

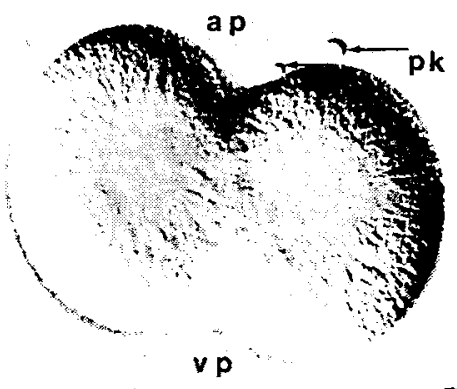

Fig. 4. Alterations of the egg shape, ejection of the polar bodies and first cleavage in dechorionated eggs of Ascidiella aspersa. The time recorded is in minutes after insemination. For details, see text. Scale bar $20 \mu \mathrm{m}$ for all figures. ap: animal pole, pk: polar body, vp: vegetative pole, 4 : cap of cytoplasm 
to the periphery of the embryo. The late gastrula with the involuted archenteron has now an ovoid shape.

\section{Neurulation}

Gastrulation is followed by neurulation which resembles that of amphibians (Berrill, 1975). The embryo lengthens, while the region of the neural ectoderm flattens and constitutes the neural plate. The neural groove originates in the midline of the neural plate and the developing neural folds fuse above the neural groove (Fig. 5I). These morphogenetic movements begin at the region of the closed blastopore and spread from the posterior to the anterior side of the neurula, thus forming the neural tube. At the end of neurulation the tail-bud stage is reached in which the neuropore is located at the antero-dorsal side (Fig. 5J).

\section{Organogenesis}

During the tail-bud stage the larval organs and the primordia of the adult organs develop (Fig. 5K). At the anterior end of the embryo three adhesive papillae arise. The gut rudiment is situated ventrally and the sensory vesicle is located dorsally at the base of the neural tube. The sensory vesicle contains two pigment spots (Fig. 5M). The anterior one, called otolith, forms part of the larval static sense organ. It is spherical and the pigment is limited to its upper half. The posterior one, named ocellus, consists of several small vesicles in the dorso-lateral part of the body wall and forms the eye of the larva. Three epidermal thickenings are present on the antero-dorsal side, each with a central depression. The anterior one represents the primordium of the pharynx, while the two posterior ones constitute the atrial primordia.

The tail of the larva exhibits the large cells of the notochord (Fig. 5L). These cells lie one behind the other and are surrounded by the dorsal neural tube, by a ventral endodermal strand and by a lateral band of muscle cells on either side of the notochord. The notochord cells undergo vacuolization during the development of the larva.

\section{Larval stage and hatching}

A larva thus developed starts performing twitching movements. Aided by both mechanical stimuli and a weakening of the chorion, which is probably caused by a hatching enzyme, the larva hatches out of the chorion to which the outer layer of follicle cells is still attached. The test cells now adhere to the tunic layer, which covers the whole larva and forms the dorsal, ventral and caudal fins (Fig. 5N). The curved tail, which was touching the head in the embryonic stages, becomes straightened out as the larva hatches. The chorda dorsalis now looks like a tube of homogeneous structure which reaches from the posterior part of the head to the end of the tail.

The free swimming stage of the larva lasts on average for five hours. At first, the larva exhibits positive phototaxis and negative geotaxis. Phototactic and geotactic reactions

Fig. 5. (A-H). Normal development of Ascidiella aspersa. A: 2-cell stage. B: 4-cell stage. C: Dechorionated 8-cell stage. D: Dechorionated 16-cell stage, seen from the animal pole: E: 16-cell stage with egg envelopes, seen from the animal pole. F: Dechorionated blastula. G: Young gastrula, some follicle cells already detached from the chorion. H: Gastrula with blastopore 

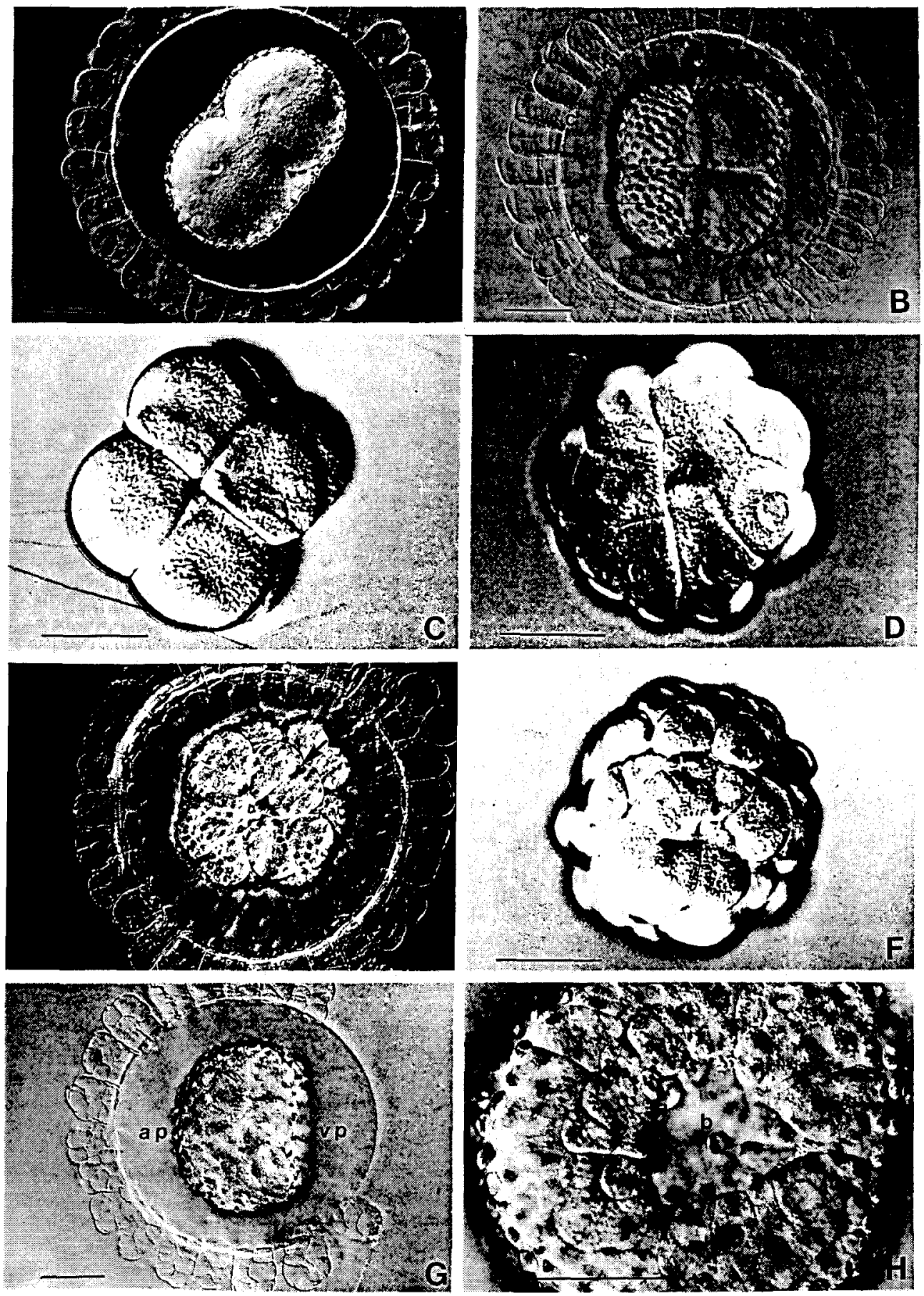

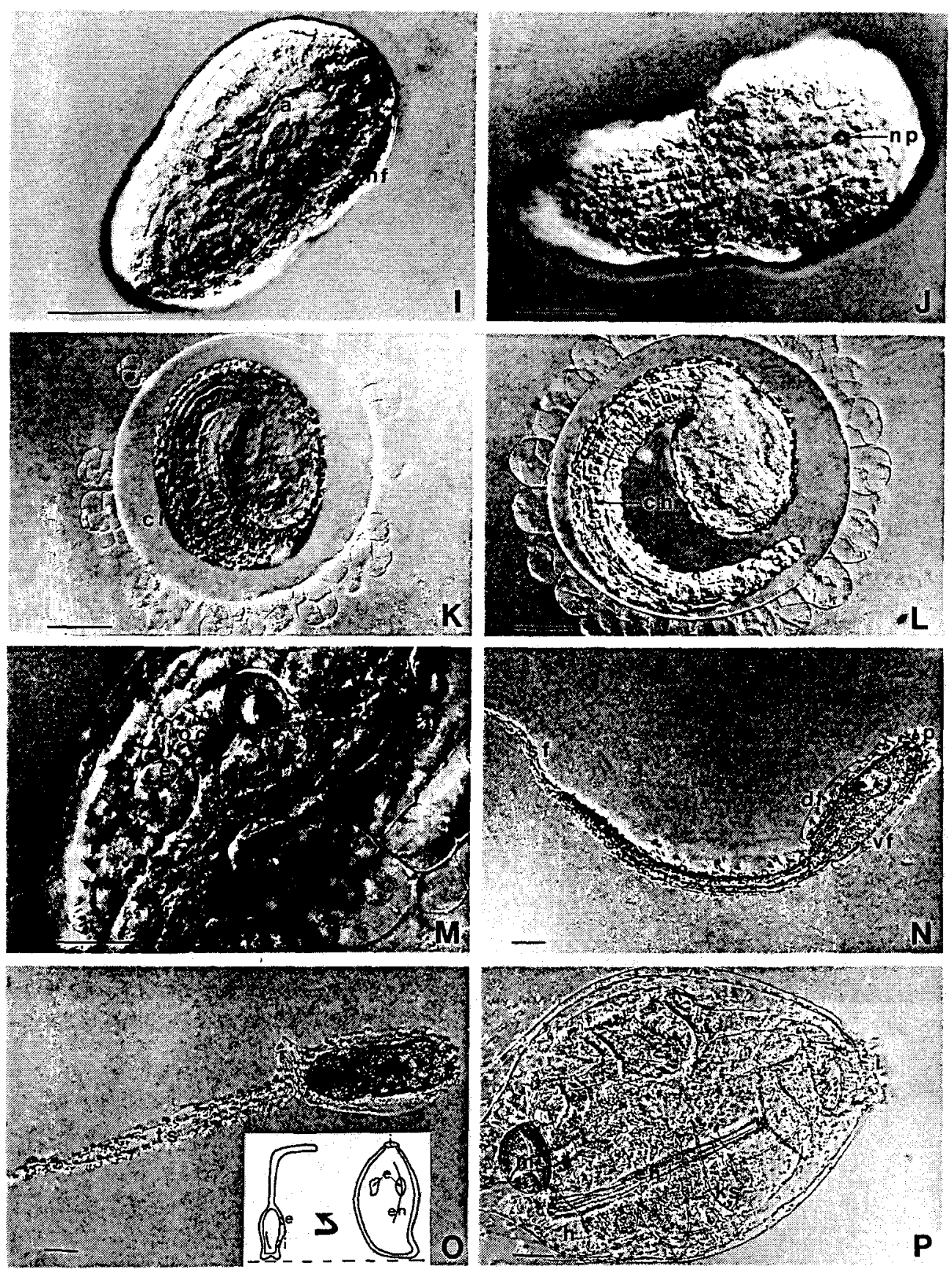
are reversed however at later stages. The larva is unable to feed during the swimming period since the intestinal system becomes functional only after metamorphosis.

\section{Metamorphosis}

As soon as the larva touches a substrate, it attaches to the surface by its adhesive papillae. When a larva fails to come in contact with a substrate, it may attach itself to another ascidian larva or even upside-down to the surface pellicle of the water. The normal development of Ascidiella aspersa from insemination to metamorphosis lasts about $24 \mathrm{~h}$ at $20^{\circ} \mathrm{C}$ (Table 1 ).

Table 1. Time course of normal development of Ascidiella aspersa at $20^{\circ} \mathrm{C}$. The data represent mean values of observations of 20 batches of eggs, each with 100 eggs, obtained from 20 different individuals

\begin{tabular}{|ll|}
\hline Age (h, min) & Developmental stage \\
\hline 00.00 & fertilized egg \\
01.00 & 2-cell \\
01.20 & 4 -cell \\
01.40 & -cell \\
02.00 & 16-cell \\
02.30 & 32-cell \\
03.00 & blastula \\
04.00 & young gastrula \\
05.00 & gastrula \\
07.30 & neurula \\
09.00 & young tail-bud \\
10.00 & tail-bud \\
12.00 & late tail-bud \\
14.00 & larva \\
17.00 & hatched larva \\
22.00 & attached larva \\
24.00 & onset of metamorphosis \\
\hline
\end{tabular}

The metamorphosis begins with the attachment of the larva. First the tail is resorbed and the tunic layer is thrown off (Fig. 5O). The persisting part of the larva undergoes radical changes during metamorphosis and the primordia of adult organs differentiate (Fig. 5P). Three days after settlement on the substrate a young ascidian is developed possessing the following organs: one pharyngeal siphon and two atrial siphons, a branchial basket with three or four pairs of branchial clefts and the endostyle, a stomach

Fig. 5. (I-P). I: Neurula with archenteron and neural folds. J: Young tail-bud stage with neuropore. K: Tail-bud stage. L: Late tail-bud stage with large notochord cells. M: Anterior portion of a fully differentiated larva, dorsal view. N: Hatched larva. O: Early stage of metamorphosis. Inset: Rotation of the main body axis during metamorphosis. P: Young ascidian. a; archenteron, ap: animal pole, b: blastopore, c: chorion, ch: chorda dorsalis, df: dorsal fin, e: atrial primordium, en: endostyle, f: follicle cell, h: heart, i: primordium of the pharynx, ks: branchial clefts, m: stomach, nf: neural fold, np: neuropore, nI: neural tube, oc: ocellus, ot: otolith, $\mathrm{p}$ : adhesive papilla, sf: caudal fin, t: test cell, ts: tunic layer, vf: ventral fin, vp: vegetative pole. Scale bars: $20 \mu \mathrm{m}$ 
and a heart changing periodically the direction of its heart-beat. During the subsequent growth phase, the two atrial siphons fuse into one and the number of branchial clefts increases.

\section{DISCUSSION}

The egg and sperm interactions during ascidian fertilization have been well studied. The spermatozoa are chemotactically guided by the follicle cells of the egg (Miller, 1975). At the chorion, recognition and binding of the gametes take place (Rosati et al., 1978; Honegger, 1986); moreover the participation of an acrosomal reaction is disputed (Woollacott, 1977; Fukumoto, 1988). Sawada et al. (1984) discovered that sperm proteases are involved in fertilization. The modification of the shape of the egg after fertilization has been investigated by Sawada and Osanai in Ciona intestinalis. A striking similarity in the modification of the egg shape after fertilization is seen in Ascidiella aspersa.

Sawada \& Osanai (1981) have discovered that in the unfertilized egg the subcortical cytoplasm contains numerous mitochondria and subcorical granules which surround the inner cytoplasm except for the area near the animal pole, where the nucleus lies. Sawada \& Osanai (1985) advance the theory that the bipolar ooplasmic segregation in the eggs of $C$. intestinalis is caused by a contractile "basket", which has its opening at the animal pole and is built by an actin filament network in the cortex of the egg. When this basket contracts after fertilization, it pushes the inner cytoplasm of low viscosity towards the animal pole and draws the viscous subcortical cytoplasm towards the vegetative pole. Thus the oolemma of the animal hemisphere is passively stretched out by the contraction of the vegetative hemisphere. Sawada (1988) points out that the movements of the subcortical cytoplasm or myoplasm belong to the first phase of ooplasmic segregation. When the myoplasm moves up again to the equatorial region after meiosis is completed, the second phase of ooplasmic segregation is reached and the myoplasmic or so-called yellow crescent is formed by this movement. During ooplasmic segregation and ensuing cleavages the mitochondria-rich myoplasm of Phallusia mammillata becomes distributed to specific cells, thereby determining their developmental fates (Zalokar \& Sardet, 1984). However, the mitochondrial localization is not the cause of muscle cell determination. Zalokar \& Sardet conclude that mitochondria only passively follow the distribution of actual muscle as well as brain cell morphogens.

Several aspects of ascidian embryogenesis have been studied by Satoh (1978), who has examined the blastula, gastrula and neurula stages of Halocynthia roretzi with the scanning electron microscope. His results hold good for A. aspersa as well. Satoh describes that at the blastula stage all cells are of nearly equal size and enclose the blastocoel. With the subsequent cell divisions the blastocoel disappears and gastrulation starts during the seventh cleavage. Satoh states that the endoderm cells only seemingly invaginate, but that in reality the broad and flat ectoderm cells push the layer of long and narrow mesoderm and endoderm cells by synchronous cell divisions. This is due to the adherence of the endoderm cells to the ectodermal layer which results in the infolding of the layer of mesoderm and endoderm cells. The resulting blastopore of the mid-gastrula is triangular with a broad anterior and a narrow posterior lip. The gastrocoel tapers down from the wide blastoporus to the narrow tip of the archenteron. During the late gastrula stage, the blastopore is shifted dorsally by epibolic movements and becomes narrow and oval. 
Neurulation begins before the blastopore is closed. The shape of the neural plate cells is modified. This modification results in the constriction of the neural groove and in the formation of the neural folds. When the plate has been folded into a tube, it is covered by the lateral ectoderm.

Many authors have emphasized the similarity of ascidian embryogenesis to that of lower vertebrates, particularly to that of amphibians. Essential parts of the body plan of ascidian tadpoles and vertebrate embryos are considered as homologous. Katz (1983) points out that the larva of Ciona intestinalis possesses a ventrally lying gut and a dorsocentrally situated notochord. The entire caudal neural tube lies dorsal to the notochord and the muscles are situated on either side of the notochord.

Acknowledgements. The help of all staff members at the BAH guest laboratories is gratefully acknowledged. Part of the investigation was supported by a GraFög grant to E. NiermannKerkenberg. Thanks are due to H. J. Poozhikalail for her critical reading of the manuscript.

\section{LITERATURE CITED}

Beneden, E. van \& Julin, C., 1887. Recherches sur la morphologie des Tuniciers. - Archs Biol., Paris $6,237-476$.

Berrill, N. J., 1950. The Tunicata, with an account of the British species. Ray Society, London, $354 \mathrm{pp}$.

Berrill, N. J., 1975. Chordata: Tunicata. In: Reproduction of marine invertebrates. II. Ed. by A. C. Giese \& J. S. Pearse. Acad. Press, New York, 2, 241-282.

Castle, W. E., 1896. The early embryology of Ciona intestinalis. - Bull. Mus. comp. Zool. Harv. 27, $201-280$.

Chabry, L., 1887. Contribution à l'embryologie normale et tératologique des ascidies simples. J. Anat. Physiol., Paris 23, 169-319.

Fukumoto, M., 1988. Fertilization in ascidians: apical processes and gamete fusion in Ciona intestinalis spermatozoa. - J. Cell Sci. 89, 189-196.

Groepler, W., 1983. Entwicklung von Ciona intestinalis (L.) (Tunicata, Ascidiaceae). - Biologie in unserer Zeit 13, 26-31.

Groepler, W., 1984. Entwicklung von Clavelina lepadiformis (Müller). - Biologie in unserer Zeit 14, 150-154.

Honegger, T. G., 1986. Fertilization in ascidians: studies on the egg envelope, sperm and gamete interactions in Phallusia mammillata. - Devl Biol. 118, 118-128.

Katz., M. J., 1983. Comparative anatomy of the tunicate tadpole, Ciona intestinalis. - Biol. Bull. mar. biol. Lab., Woods Hole 164, 1-27.

Miller, R. L., 1975. Chemotaxis of the spermatozoa of Ciona intestinalis. - Nature, Lond. 254, $244-245$.

Pflugfelder, O., 1970. Lehrbuch der Entwicklungsgeschichte und Entwicklungsphysiologie der Tiere. Fischer, Stuttgart, 347 pp.

Rosati, F. \& De Santis, R., 1978. Studies on fertilization in the ascidians. I. Self-sterility and specific recognition between gametes of Ciona intestinalis. - Expl Cell Res. 112, 111-119.

Satoh, N., 1978. Cellular morphology and architecture during early morphogenesis of the ascidian egg: an SEM study. - Biol. Bull. mar biol. Lab., Woods Hole 155, 608-614.

Sawada, T. \& Osanai, K., 1981. The cortical contraction related to the ooplasmic segregation in Ciona intestinalis eggs. - Wilhelm Roux Arch. EntwMech. Org. 190, 208-214.

Sawada, H., Yokosawa, H., Someno, T., Saino, T. \& Ishii, S., 1984. Evidence for the participation of two sperm proteases, spermosin and acrosin, in fertilization of the ascidian Halocynthia roretzi: inhibitory effects of leupeptin analogs on enzyme activities and fertilization. - Devl Biol. 105 , 246-249.

Sawada, T. \& Osanai, K., 1985. Distribution of actin filaments in fertilized egg of the ascidian Ciona intestinalis. - Devl Biol. 111, 260-265. 
Sawada, T., 1988. The mechanism of ooplasmic segregation in the ascidian egg. - Zool. Sci. 5 , $667-675$.

Woollacott, R. M., 1977. Spermatozoa of Ciona intestinalis and analysis of ascidian fertilization. J. Morph. 152, 77-88.

Zalokar, M. \& Sardet, C., 1984. Tracing of cell lineage in embryo-development of Phallusia mammillata (Ascidia) by vital staining of mitochondria. - Devl Biol. 102, 195-205. 